\title{
Gelo ethnicity water resources artistic design and utilization
}

Xi Zhou ${ }^{1,2}$, Kaige Liu ${ }^{2}$ and DeXiang Deng ${ }^{1,2, *}$

${ }^{1} \mathrm{Xi}$ 'an Jiaotong University. School of Human Settlements and Civil Engineering. 710049

No.28Xianning west Road. Beilin District. Xi'an, China.

${ }^{2}$ Chongqing University of Posts and Telecommunications. College of Media and Arts. 400065 No.2 Chongwen Road. Chongqing, China.

\begin{abstract}
The artistic design and utilization of water resources have been in the field of the urban landscape for a long time, but the artistic design and utilization of rural water resources have hardly touched. Based on Gelo ethnicity religion, ecological collective unconscious, art, culture, traditional production, and living water, etc. on the basis of research conducted on the research of artistic design and enriched Gelo ethnicity superposition in the function of water resources utilization in additional value, based on this point, move Gelo ethnicity construction of modern ecological civilization leads the ecological economy and the development of national cultures.
\end{abstract}

Keywords: Gelo ethnicity; water resources; artistic utilization

The artistic design and utilization of water resources were first accompanied by the design of architecture and landscape, such as the lomat levie fountain, the flowing water villa on the Banks of the bear creek river in the suburb of Pittsburgh, the dragon spits water in the imperial garden of China, and the small Bridges and flowing water in the private

*Corresponding author: 2377230006@qq.com 
garden of China, all of which are examples of artistic utilization of water resources. With the development of science and technology, there are many new ways to use the artistic design of water resources, such as water screen films, music fountains, etc. The artistic use of these water resources brings people a strong visual, auditory feeling, and novel experience. These are basically the artistic design and utilization of urban water resources, but at present, the artistic design and utilization of rural water resources have hardly been touched.

Based on the background of rural revitalization and the perspective of national development, this paper bases on the purpose of co-development and utilization of the culture, tourism, and industry of the Gelo ethnicity, takes the rich water resources of the Gelo ethnicity as the fulcrum, the unique artistic and cultural resources as the lever, and the artistic utilization of water resources as the driving force to promote the rural revitalization and national development of the Gelo ethnicity. At the same time, for the rural water resources of the artistic design and use and research.

\section{The spark of Gelo ethnicity 's artistic design of water resources}

Gelo ethnicity is a minority nationality with a long history in China. At present, the Gelo ethnicity has 550,000 people, more than $90 \%$ of whom live in Daozhen county, Wuchuan county, and Shiqian county of Guizhou province in the Furong river basin.

Gelo ethnicity generation live traffic inconvenience, steep mountain road, land barren, survival wisdom gave birth to the national religious beliefs, with thoughts of fear nature, all things have spirit that natural things to protect their survival, formed the Gelo ethnicity "hold" the ecological view, in the development of thousands of years of national keep the harmony between human and nature, construct Gelo ethnicity beautiful ecological environment.

The animism faith and ecological consciousness of Gelo ethnicity religion are the genes of its national artistic spirit, which continuously generates the rich artistic culture of Gelo ethnicity and accumulates rich artistic and cultural resources. Because Gelo ethnicity is located in an isolated mountainous area, the artistic culture is not impacted by the foreign culture, and the artistic culture has its own system, unique characteristics, and continuity, among which there are more than 40 items of national, provincial and municipal intangible cultural heritages.

"Every ancient culture has its own hard cultural core, which is the value and source of life of this culture, and the foundation for a culture to be different from other cultures" [1] In the artistic culture of Gelo ethnicity, the carrier of its religious belief and the external manifestation form, together with the animism belief, continuously build up the value of the collective unconsciousness of the ecological concept of "protecting and maintaining." 
Based on this, the value chain of Gelo ethnicity's faith, ecology, and art should play a greater role in the Gelo ethnicity's contemporary and future.

Gelo ethnicity settlements in the way of true county, WuChuan County and Shi Qian next to a belt, subtropical monsoon climate, abundant precipitation, it is located in the Yunnan-Guizhou Plateau in the northeast of Sichuan basin to the transition of slope zone, complex terrain, landscape diversity, changeable, here is rich in water resource and present a variety of forms, rivers, have formed, springs, waterfalls, fold flow, cliff cave jet, springs, springs, emerge in endlessly. Its abundant water resources and water forms are closely related to Gelo ethnicity's worship, ecological view, and artistic value, except for its specific geographical climate. This paper hopes to become the breakthrough point of the Gelo ethnicity 's faith, ecology, and art value chain to exert great energy through the study of " Gelo ethnicity nationality's artistic design and utilization of water resources."

Based on the investigation and demonstration of the current situation of water resources utilization, production, and life, as well as the trend of water resources utilization of social development in the Gelo ethnicity -inhabited areas, this paper, put forward some ideas of artistic utilization for the co- Gelo ethnicity -inhabited areas.

\section{The artistic design and utilization of the constructed modern water conservancy projects}

Gelo ethnicity settlement by Wuling throughout south branch, relief change is bigger, is rich in water resource, water level, big difference, the development of many large and small hydropower stations, some lie across rivers and streams, some attach slope, the water resource utilization in modern engineering design "a large part of the designer in the actual water resources and hydropower design lack of positive application of the concept of ecological consciousness, this leads to more in water resources, and hydropower design emphasizes the function of water resources and hydropower engineering" [2], ignore the engineering damage to the environment, water diversion canals, plant morphology, the pressure piping, LanShui dam crude exposure, The destruction of the surrounding vegetation and soil by the engineering construction has become the scar of the surface, and the downstream riverbed and gully dry up after interception. The ecological civilization of the Gelo ethnicity ancestors has been eroded by modern technology, and the visual environment has been polluted to some extent.

In order to realize the docking or integration of the traditional ecological civilization and modern industrial civilization of Gelo ethnicity and increase the environmental ecology and visual ecology value of water conservancy project, the artistic design and utilization of water resources utilization project of hydropower station are carried out. If possible, it can be transformed into engineering technology to display educational value, ecological tourism 
value, or sightseeing tourism value through artistic design. Such as Daozhen Furong River Guanzhuang hydropower station can be artistically designed and treated for its water-retaining dam, endowing it with the implication of ecological consciousness or decorative treatment of national artistic characteristics, and through the artistic way to increase the sense of integration between modern hydropower station and Gelo ethnicity, as well as the sense of docking between traditional civilization and modern civilization. The damaged vegetation and surface of the project can be restored by garden design or artistically restored according to local conditions to add scenery to rural tourism. For the pressure pipeline or water transmission pipeline of the bare water conservancy project, the artistic figure of water worship of the Gelo ethnicity can be designed to spread the ecological consciousness of the Gelo ethnicity, water wisdom, and art culture, and form a differentiated scenic spot.

Built for modern production and living water, mountain pool dam reservoir lateral slope and dam plane, artistic design of ecological restoration processing, plant with the surrounding environment coordination vegetation to make it into the surrounding environment, the landscape design or design type, modern art design in the ecological restoration of visual appreciation effects. Through the artistic design, the artistic design and utilization of the surface of the rammed earth project for the utilization of water resources can produce a good visual experience effect in the function of ecological restoration, soil conservation, and slope protection. If there are conditions, this idea can be used to cooperate with the artistic design of water to develop into an ecological tourism scenic spot.

\section{The new design of water resources utilization engineering artistry enhancement design}

For the newly designed water resources utilization project, the integration of regional, terrain, culture and other artistic design based on function should be carried out, the personalized and artistic design such as engineering art form, respective color, ecological greening should be strengthened, the multiple overlapping of functional benefit, ecological effect, visual beauty, cultural bearing and tourism value of water resources utilization should be highlighted, and the Gelo ethnicity water resources should be explored as the value chain of core utilization to realize the maximum utilization of water resources.

For example: the same drop-water pressure pipeline or water pipeline, using modern science and technology, the whole section or the pipeline section with rich tourist resources or the pipeline section with large traffic flow, is designed as a transparent pipeline, enriching tourism resources or creating a tourist attraction., Intuitive experience of science and technology and water pressure energy. Concealed design of some water conservancy projects and facilities can also be integrated into the ecological environment. 
Corresponding to some high-tech water resource utilization engineering designs, core science and technology demonstration and experiential design can be performed to show the science and technology and equipment operation process and develop into technology Experience tourism, superimposed experience tourism value.

\section{The artistic design and utilization of traditional water resources facilities}

Gelo ethnicity ecological collective unconscious built up Gelo ethnicity water ecological wisdom, and the construction of the rich and colorful water facilities, its facilities and water process full of religious rituals and artistic feeling, but in the process of modernization, social industrialization under the population outflow and the excessive dependence on the modern water conservancy projects, water ecological consciousness gradually fade, waterway change, many traditional water facilities damaged, unattended maintenance. These facilities and methods, such as water-preserving shi kan terrace, water-storing stone base well and water-fixation hybrid method, are the crystallization of the ecological water wisdom of the Gelo ethnicity people, bearing the ecological value, water utilization thought and cultural and artistic value, which are the valuable cultural heritage left by the ancestors, and should be restored and restarted for utilization or protective development and utilization.

In the process of restoration or conservation development, it should explore its heritage value, cultural value, ecological value, and functional value, and ensure its individual restoration and characteristic development. For example, the water storage stone dike terraces combined with the terrain, sight, perspective, season, humanistic spirit and other conditions, artistically designed and developed their tourism resources based on the functions of water conservation and planting. For example, in some dams, slopes, etc. that have overlooking conditions or open fields of vision, the order and position of mixed plants can be artistically designed based on the solid-water mixing method, or developed into mixed designs with different colors and flowers .Realize the planting of mixed plants with graphics, patterns, text, and pictures, forming a landscape for rural sightseeing and tourism destinations such as viewing, photography, and sketching. Repairing water storage Shilei wells as a supplement to modern water conservancy projects, artistically designing and developing restoration and utilization of conditional water storage Shi Lei wells, or religious ritual procedures to restore water use, making it a water storage utilization, religion The spiritual pillar of the water faith, the carrier of water wisdom, and the place of religious rituals have become Gelo ethnicity cultural tourist attractions.

\section{Conclusion}


This paper briefly discusses these aspects, and we will discuss other fields of Gelo ethnicity water resources, artistic design, and utilization in the following research articles.

Gelo ethnicity artistic design by using water resources, and should follow the national religion, art, culture, production life style, the basis of ecological value, into the modern life needs, aesthetic orientation, the art and science and technology of functional design of ecological tourist attractions or the development of cultural tourism landscape design, Gelo ethnicity ecological civilization construction, the coordinated development of national economic prosperity, cultural prosperity integration. The local government should strengthen the macroscopic guide and micro control, establish the functional use of water resources and the artistic use of collaborative mechanism and supervision mechanism of examination and approval, guaranteed the personalized design and differentiation of water resources utilization, at the same time to carry on the design property protection, prevent replication apply, guarantee a top attractions, rich culture, and tourism resources, Gelo ethnicity towards ecological economy, industrial economy is complementary of national development.

\section{References}

1. L. fang, L. Zhongchang. Studies on guizhou nationalities. J.(2015)

2. L. Zhongchang. Journal of zunyi normal university. J. (2009)

3. F. Wei. Engineering construction and design. J. (2018)

4. G. Jinling. Fujian Agriculture and Forestry University. D. (2018)

5. L. Ruihui. Science and Technology Economics. J. (2018)

6. Y. Suzhou University of Science and Technology. D. (2019)

7. C. Shenghua. Shandong Jianzhu University. D. 2019.

8. Y. Dongyan, G. Chuanchu. Journal of the Party School of CPC Zhengzhou Municipal Committee. J. (2019)

9. Z. Qianqian, G. Dazhi. Journal of Qingdao Technological University. J. (2018)

10. L. Chang. Chinese and Foreign Architecture. J. (2016)

11. C. Yiyong, Y. Kongjian. China Water Resources. J. (2015)

12. D. Ningrui, T. Wenzhuan. Modern Urban Studies. J. (2015)

13. Y. Kongjian, C. Yiyong. China Water Resources. J. (2014)

14. Z. Fangying, L. Baosuo, C. Yuting, Y. Zhiqiong, L. Jiangfeng. Beijing Water Affairs. J.S2 (2009) 
15. Y. Yizun, W. Kelin, C. Hongsong. Research of Agricultural Modernization. J. (2009)

16. Y. Kongjian, Z. Lei. Journal of Hydraulic Engineering. J. (2008)

17. L. Qi, Z. Likun. Agriculture and Technology. J. (2019)

18. C. Hong. Management and Technology of Small and Medium-sized Enterprises. J. (Late Issue ,2018)

19. C.Yizhi. Theoretical Research on Urban Construction.J. (Electronic Edition ,2018)

20. J. Zhan. Low Carbon World. J. (2017)

This dissertation is: the intermediate results of the Chongqing postgraduate scientific research and innovation project "Research and Practice of Gelo Art Culture and Rural Revitalization of Kinetic Energy" (Project No : CYS19258);

Chongqing University of Posts and Telecommunications University Research and Training Plan Project "Design Empowering Gelo Precise Poverty Alleviation and Rural Development" Revitalization Research "interim results. 